\title{
Article
}

\section{Spray-Dried Proliposome Microparticles for High-Performance Aerosol Delivery Using a Monodose Powder Inhaler}

Omer, Huner K., Hussein, Nozad R, Ferraz, Amina, Najlah, Mohammad, Ahmed, Waqar, Taylor, Kevin M G and Elhissi, Abdelbary M A

Available at http://clok.uclan.ac.uk/23206/

Omer, Huner K., Hussein, Nozad R, Ferraz, Amina ORCID: 0000-0002-59132863, Najlah, Mohammad, Ahmed, Waqar, Taylor, Kevin M G and Elhissi, Abdelbary M A (2018) Spray-Dried Proliposome Microparticles for HighPerformance Aerosol Delivery Using a Monodose Powder Inhaler. AAPS PharmSciTech, 19 . pp. 2434-2448.

It is advisable to refer to the publisher's version if you intend to cite from the work. http://dx.doi.org/10.1208/s12249-018-1058-4

For more information about UCLan's research in this area go to

http://www.uclan.ac.uk/researchgroups/ and search for <name of research Group>.

For information about Research generally at UCLan please go to http://www.uclan.ac.uk/research/

All outputs in CLoK are protected by Intellectual Property Rights law, including Copyright law. Copyright, IPR and Moral Rights for the works on this site are retained by the individual authors and/or other copyright owners. Terms and conditions for use of this material are defined in the policies page. 
Spray-dried proliposomes for aerosol delivery

\section{Spray-Dried Proliposome Microparticles for High Performance Aerosol}

\section{Delivery using a Monodose Powder Inhaler}

${ }^{1,2}$ Huner K. Omer, ${ }^{1,2}$ Nozad R. Hussein, ${ }^{1}$ Amina Ferraz, ${ }^{3}$ Mohammad Najlah, ${ }^{4}$ Waqar Ahmed, ${ }^{5}$ Kevin M.G. Taylor ${ }^{* 6,7}$ Abdelbary M.A. Elhissi

${ }^{1}$ Institute of Nanotechnology and Bioengineering, School of Pharmacy and Biomedical Sciences, University of Central Lancashire, Preston PR1 2HE, United Kingdom

${ }^{2}$ College of Pharmacy, Hawler Medical University, Erbil, Iraq

$\underline{{ }^{3} \text { Faculty of Medical Science, Anglia Ruskin University, Chelmsford CM1 1SQ, United Kingdom }}$

${ }^{4}$ Nanoscience Research Group, School of Mathematics and Physics, College of Science, University of Lincoln, Lincoln LN6 7TS, United Kingdom

${ }^{5}$ UCL-School of Pharmacy, 29-39 Brunswick Square, London WC1N 1AX, United Kingdom

${ }^{6}$ Research Planning and Development, Office of Vice President for Research and Graduate Studies, Qatar University, P.O. Box 2713, Doha, Qatar

$\underline{{ }^{7} \text { College of Pharmacy, Qatar University, P.O. Box 2713, Doha, Qatar }}$

\section{*Corresponding author:}

Abdelbary Elhissi

Manager of Research Excellence, Research Planning and Development,

Office of Vice President for Research and Graduate Studies,

Qatar University, Doha, Qatar

and

College of Pharmacy

Qatar University

P.O. Box 2713

Doha, Qatar

Tel: +97444035632

Fax: +974 44035551

E-mail: aelhissi@qu.edu.qa or aelhissi@gmail.com 
Spray-dried proliposomes for aerosol delivery

42

43

44

45

\section{Abstract}

Proliposome formulations containing salbutamol sulphate (SS) were developed using spray drying, and the effects of carrier type (lactose monohydrate (LMH) or mannitol) and lipid to carrier ratio were evaluated. The lipid phase comprised soy phosphatidylcholine (SPC) and cholesterol (1:1), and the ratios of lipid to carrier were 1:2, 1:4, 1:6, 1:8 or 1:10 w/w. X-ray powder diffraction (XRPD) revealed an interaction between the components of the proliposome particles, and scanning electron microscopy (SEM) showed that mannitol-based proliposomes were uniformly sized and spherical, whilst LMH-based proliposomes were irregular and relatively large. Using a two-stage impinger (TSI), fine particle fraction (FPF) values of the proliposomes were higher for mannitol-based formulations, reaching $52.6 \%$, which was attributed to the better flow properties when mannitol was used as carrier. Following hydration of proliposomes, transmission electron microscopy (TEM) demonstrated that vesicles generated from mannitol-based formulations were oligolamellar, while LMH-based proliposomes generated "worm-like" structures and vesicle clusters. Vesicle size decreased upon increasing carrier to lipid ratio, and the zeta potential values were negative. Drug entrapment efficiency (EE) was higher for liposomes generated from LMH-based proliposomes, reaching $37.76 \%$ when 1:2 lipid to carrier ratio was used. The in vitro drug release profile was similar for both carriers when 1:6 lipid to carrier ratio was used. This study showed that spray drying can produce inhalable proliposome microparticles that can generate liposomes upon contact with an aqueous phase, and the FPF of proliposomes and the EE offered by liposomes were formulationdependent.

Key words: Aerosol; Morphology; Particle size; Powder; Pulmonary 
Spray-dried proliposomes for aerosol delivery

\section{Introduction}

Inhalation of therapeutic materials in liposome formulations has been studied as a strategy for controlled drug release in the lungs. There is evidence that liposomes can retain the drug in the pulmonary tissues for prolonged periods, reducing the need for frequent dosing and minimizing the potential of systemic adverse effects (1-5). Many studies have investigated the pulmonary delivery of relatively large volumes of liposome dispersions using medical nebulizers $(1,6,7)$. There are at least two nebulizable liposome formulations currently in clinical trials for potential approval in the treatment of pulmonary infections, for example, Arikace ${ }^{\circledR}$ (liposomal Amikacin) for the treatment of pseudomonas aeruginosa in cystic fibrosis patients $(7,8)$, and Pulmaquin ${ }^{\circledR}$ (liposomal ciprofloxacin) for the treatment of non-cystic fibrosis lung infections (9).

Although nebulization is the most studied means of delivering liposomes by inhalation, there are a number of disadvantages associated with using nebulizers for this purpose. First, liposome instability caused by shearing during nebulization and concomitant losses of the originally entrapped drug is a major challenge, necessitating extensive work to engineer the optimal liposome size and bilayer composition, and select nebulizers with appropriate designs and operating parameters $(7,10)$. Second, the performance of the aerosol (e.g. output, droplet size, 'FPF', etc.) generated from these nebulizers is greatly influenced by the physicochemical properties of formulation $(11,12)$, which means that nebulizer performance for one liposome dispersion may not be the same for another formulation (13). Third, the large volumes delivered via nebulizers may contribute to toxicity not only by the drug but also by the accompanying excipients. For example, in pulmonary infections, inhalation of relatively large antibiotic doses is needed to eradicate the infection, necessitating the use of large phospholipid quantities to entrap the antibiotic and sustain its release. In spite of the established biocompatibility and biodegradability of liposomes, dose-limiting toxicity of phospholipids in animals has been reported (14). 


\section{Spray-dried proliposomes for aerosol delivery}

Dry powder inhalers (DPIs) offer the advantages of delivering small doses of drug and excipients, and avoidance of shearing-induced liposome instability during delivery. Compared to the number of studies published for the delivery of liquid liposome dispersions via nebulization, a limited number of reports have attempted to explore the potential of liposomes and phospholipid formulations for pulmonary applications delivered in the dry powder form. It has been postulated by several investigators that dried liposomes would exploit the aqueous environment of the lung to be hydrated in situ within the respiratory tract (5). Freeze-drying of liposomes in the presence of a cryoprotectant followed by micronization has been studied for the generation of inhalable dry powder liposomes; however, milling may exert a deleterious effect on vesicle stability, causing leakage of the drug upon rehydration $(15,16)$. As an alternative to freeze-drying (lyophilization), spray-drying of liposomes dispersed in carbohydrate solutions has been investigated, with high powder 'respirability' being reported in a range of studies (17-21).

As an alternative to traditional liposome powders, particulate proliposome formulations have been developed for inhalation. Proliposomes are carbohydrate carriers coated with phospholipid to generate liposomes upon addition of aqueous phase $(22,23)$. Proliposomes, in the context of this study, are phospholipid and drug blended with diluent carbohydrate carriers, aiming to generate liposomes upon contact with the pulmonary physiological milieu (5). In one approach, phospholipid and drug were mixed with lactose followed by air-jet milling. The resultant proliposome blend generated multilamellar vesicles (MLVs) upon dispersion in aqueous phase, with entrapment efficiencies (24) and fine particle fractions (FPF) (25) being dependent on formulation. Spray drying of alcoholic phospholipid solutions may also generate proliposome particles (26-28) with FPFs in the range of $20-30 \%$ using antibiotics such as pyrazinamide (28). Thus, the potential of inhalable proliposome powders has been explored for delivering antimicrobial drugs. Although the antibacterial activity of hydrated proliposome has been established in vitro (27), the need for large doses for the eradication of lung infections in vivo raises doubts about the suitability of DPIs in delivering therapeutic amounts of antimicrobial agents. Unlike pulmonary infections, the doses needed to treat 


\section{Spray-dried proliposomes for aerosol delivery}

asthma are very small, hence powdered formulations (e.g. in the form of proliposomes) can potentially be used as antiasthma delivery systems

In this study, we have introduced a potentially applicable approach for pulmonary delivery using spray-dried proliposomes loaded with salbutamol sulphate (SS). Proliposomes consisted of carbohydrate carriers (lactose monohydrate or mannitol) and lipids (soya phosphatidylcholine and cholesterol; 1:1) were formulated using a range of lipid to carriers ratios. The resultant proliposome powders were thoroughly characterized, and using a two-stage impinger (TSI), the deposition of the drug was evaluated following proliposome delivery from a Monodose inhaler device. Furthermore, the ability of the proliposomes to generate liposomes following hydration was studied and drug entrapment was determined, to evaluate the potential of the formulations in providing a reservoir, in situ, for sustaining the drug release. The findings of this study using proliposomes were evaluated in light of the progress achieved in the field of pulmonary delivery of dry powder formulations.

\section{Materials and methods}

\subsection{Materials}

Lactose monohydrate (LMH) was purchased from VWR, UK, and D-mannitol and cholesterol (CH) were bought from Sigma Aldrich, UK. Solvents used in HPLC experiments including Water and methanol were HPLC-grade and HPLC-grade 99.9\%, respectively and were supplied by Fisher Scientific, UK. Absolute ethanol and ethanol (96\%) were also purchased from Fisher Scientific, UK. Sodium 1-hexane sulfonate monohydrate (99\%), acetic acid glacial (99\%) and salbutamol sulphate (SS; 99\%) were purchased from Alfa-Aesar, UK. The phospholipid used, namely soya phosphatidylcholine (SPC; Lipoid S-100) was kindly gifted by Lipoid, Switzerland. 
Spray-dried proliposomes for aerosol delivery

\subsection{Methods}

\subsubsection{Spray drying of mannitol and LMH}

Carbohydrate carriers (LMH or mannitol) were spray-dried by dissolving the carrier particles in distilled water $(1 \% \mathrm{w} / \mathrm{v})$, followed by spraying the carbohydrate solution through the spray-drier's nozzle $($ diameter $=0.7 \mathrm{~mm})$ using a B-290 spray drier (Büchi, Switzerland). The inlet temperature was set at $130^{\circ} \mathrm{C}$, spraying flow rate was $600 \mathrm{~L} / \mathrm{h}$, feed rate was $17 \%$, and the outlet temperature was $70 \pm 2^{\circ} \mathrm{C}$. The resultant spray-dried microparticles were used as core carriers to prepare particulatebased proliposomes. This step of spray drying aimed for enhancing the dispersion of the carbohydrate carriers in ethanol during the preparation of proliposomes, as described in the subsequent section.

\subsubsection{Manufacture of particulate-based proliposome particles via spray drying}

The constituents used to prepare proliposomes are demonstrated in Table 1. Spray-dried mannitol or LMH microparticles were employed as core carriers for manufacturing proliposomes. This was achieved by weighing a total of $100 \mathrm{mg}$ lipid consisting of SPC and $\mathrm{CH}$ (1:1 mole/mole), followed by addition of $100 \mathrm{~mL}$ ethanol (96\% grade), and SS (10 mg). The alcoholic mixture was sonicated for $1 \mathrm{~min}$ to aid complete dissolution of lipids in ethanol. The spray-dried mannitol or LMH in various ratios were dispersed in the ethanolic solution followed by sonication for 15 min to break up any agglomerates of the carbohydrate particles before performing spray drying using the same Buchi B290 Mini Spray Dryer equipment, but this time connected with the Buchi's inert loop system (Buchi, Switzerland). The homogeneity of the resultant alcoholic mixture was maintained by continuous stirring while feeding the mixture into the spray drier. The spray drying conditions were optimized by adjusting the inlet temperature at $120^{\circ} \mathrm{C}$, spray flow rate was $600 \mathrm{~L} / \mathrm{h}$, feed rate was $11 \%$ and the outlet temperature was $73 \pm 3^{\circ} \mathrm{C}$. The resultant powder constituting lipid/carbohydrate was collected and referred to as 'proliposomes', which were stored in a desiccator for later use in the same day. 
Spray-dried proliposomes for aerosol delivery

\subsubsection{Hydration of spray-dried powder}

Samples of spray-dried powders were hydrated by adding deionized water followed by vortex mixing for $2 \mathrm{~min}$ in order to test for the possible generation of liposomes. The liposome dispersion was allowed to "anneal" for around $1 \mathrm{~h}$ at room temperature before performing further characterization. Allowing the liposomes to anneal at temperatures above that of the lipid phase transition $\left(\mathrm{T}_{\mathrm{m}}\right)$ may promote the stability of liposomes by overcoming structural defects of the bilayers [29].

\subsubsection{Product yield estimation}

The product yield $(P Y)$ of spray-dried powders was determined using the weight of the final spraydried powder $\left(W^{\circ}\right)$ divided by the initial weight of carrier, lipid and drug employed $(W T)$. The product yield, drug recovery and content drug uniformity were determined according to the following equations (30):

$$
P Y(\%)=\frac{W^{\circ}}{W T} \times 100 \quad E q .1
$$

$$
\text { Drug recovery }(\%)=\frac{P w}{W T} \times 100 \quad E q .2
$$

Where $P w$ is the practical weight of the drug after spray-drying was performed, as quantified using high performance liquid chromatography (HPLC).

$$
\text { Content drug uniformity }(\%)=\frac{\text { Drug recovery }(\%)}{P Y(\%)} \times 100 \quad \text { Eq.3 }
$$


Spray-dried proliposomes for aerosol delivery

\subsubsection{Scanning electron microscopy (SEM)}

Particle size and morphology of spray-dried formulations were studied using scanning electron microscopy (SEM, Quanta-200, FEI at $20 \mathrm{kV}$ ). Spray-dried particles were spread onto an aluminium stub and coated with a film of gold using the JFC-1200 Fine Coater (JEOL, Tokyo, Japan).

\subsubsection{X-ray powder diffraction (XRPD) studies}

X-ray diffraction (XRPD) studies of powder were performed by utilizing the Equinox 2000 (Inel, France) using a diffracted-beam monochromator with $\mathrm{Cu}$ radiation. The intensity of diffractions was recorded at an angle of 2-theta, at a diffraction scan duration of $20 \mathrm{~min}$. The experiments were conducted by keeping the voltage at $32 \mathrm{kV}$ and the current generator at $28 \mathrm{~mA}$.

\subsubsection{Studies of vesicle morphology using transmission electron microscopy (TEM)}

A drop of hydrated spray-dried powder was carefully positioned on carbon-coated copper grids (400 mesh; TAAB Laboratories Equipment Ltd., UK), followed by negative staining (using 1\% phosphotungstic acid; PTA). The samples were imaged using the Philips CM 120 Bio-Twin electron microscope (Philips Optics BV, the Netherlands).

\subsubsection{Particle size measurements of hydrated samples}

Size and size distribution of liposomes generated upon hydration of spray-dried proliposomes were analysed by laser diffraction using the Mastersizer 2000 (Malvern Instruments Ltd., UK). The median size, also referred to as volume median diameter (VMD; 50\% undersize), and Span were measured to represent the size and size distribution (polydispersity) of liposomes, respectively. Span value 
Spray-dried proliposomes for aerosol delivery

represent the difference between $90 \%$ undersize and $10 \%$ undersize divided by the VMD. Span is a unit-less term introduced by the manufacturer of the Malvern Mastersizer 2000 instrument.

\subsubsection{Zeta potential measurements}

The zeta potential of vesicles was determined via the Zetasizer Nanoseries instrument (Malvern Instruments Ltd., UK) by choosing the relevant software option of the instrument. Proliposomes were hydrated with deionized water with shaking. The resultant liposomes $(70 \mu \mathrm{L})$ were loaded via a Gilson pipette into the Malvern's zeta potential cells, after setting the temperature at $25^{\circ} \mathrm{C}$ and allowing $2 \mathrm{~min}$ for sample equilibration in order to obtain consistent zeta potential measurements.

\subsubsection{Drug content and entrapment efficiency (EE) studies}

Spray-dried powder $(10 \mathrm{mg})$ was dispersed with deionized water $(1 \mathrm{~mL})$ to generate liposomes. The dispersion was transferred into a volumetric flask $(10 \mathrm{~mL})$, and methanol $(1 \mathrm{~mL})$ was added to dissolve the lipid followed by making up the volume with water. HPLC was employed to determine the drug content in the flask (i.e. total drug loaded into the $10 \mathrm{mg}$ powder sample) by adapting a method we published established (13). The mobile phase was made by making a buffer solution constituting a mixture of sodium hexane sulfonate in water $(5 \mathrm{mM})$ and methanol $(75: 25 \mathrm{v} / \mathrm{v})$, to which glacial acetic acid was added to have $1 \%$ of the total volume. The high-performance liquid chromatography (HPLC; Agilent 1200 - UV detector system; Hewlett-Packard Co., USA) was set up with a Symmetry C-18 column (150 mm, $4.6 \mathrm{~mm}, 5 \mathrm{~m}$; Waters, UK). The samples (injection volume of each is $20 \mu \mathrm{L}$ ) were analysed at $276 \mathrm{~nm}$. The flow rate of mobile phase was set up at $1 \mathrm{~mL} / \mathrm{min}$ at $40{ }^{\circ} \mathrm{C}$. To determine the entrapment efficiency (EE), spray-dried powder (10 mg) was hydrated using deionized water $(50 \mu \mathrm{L})$ followed by vortex mixing for 2 min and dilution with deionized water $(950 \mu \mathrm{L})$. The liposomes were left for $1 \mathrm{~h}$ at room temperature to anneal, followed by further dilution to $8 \mathrm{~mL}$ with deionized water. The liposomes were then centrifuged at 55,000 rpm $(277,000 \mathrm{x} \mathrm{g})$ for 
Spray-dried proliposomes for aerosol delivery

35 min at $6^{\circ} \mathrm{C}$ (Beckman LM-80 ultracentrifuge; Beckman Coulter Instruments, USA). The supernatant was aspirated for subsequent analysis of SS (the unentrapped fraction of drug). The EE was determined using the following equation:

$$
E E(\%)=\frac{\text { Total drug loading }- \text { Unentraped drug }}{\text { Total drug loading }} \times 100 \quad \text { Eq. } 4
$$

\subsubsection{In vitro drug release study}

The release of SS from liposomes generated from the proliposome powders was investigated using the dialysis method. Spray-dried powder (71 mg containing $1 \mathrm{mg} \mathrm{SS}$ ) was dispersed with deionized water $(0.5 \mathrm{~mL})$ followed by vortex mixing for $1 \mathrm{~min}$ and dilution with deionized water $(1.5 \mathrm{~mL})$ to generate liposomes. The dispersion was placed in a dialysis tube (MWCO 3500) and tightly sealed. For free drug, $1 \mathrm{mg}$ SS was dissolved in $1 \mathrm{ml}$ of ethanol: water: tween 80 (20:79.9:0.1\%). Then, the dialysis tube was immersed in $50 \mathrm{~mL}$ (total volume) release medium (deionized water) containing $0.1 \%(\mathrm{v} / \mathrm{v})$ Tween 80$)$ and incubated with stirring in for $24 \mathrm{~h}$ at $37^{\circ} \mathrm{C}$. Samples $(0.3 \mathrm{~mL})$ were taken at time intervals from the release medium for $24 \mathrm{~h}$, and replaced by a similar volume of fresh medium. The concentration of SS was determined by HPLC using the methods described above.

\subsubsection{Assessment of aerosol performance in vitro}

Using the Two-Stage Impinger (TSI), also called the Twin Impinger or the Single Stage Glass Impinger (Copley Scientific Ltd, Nottingham, UK), the performance of spray-dried proliposome aerosols and deposition profile were investigated (31) using a Miat Monodose powder inhaler (Miat, Italy). TSI is designed with two stages: the upper stage (S1) and the lower stage (S2), attempting to represent the upper airways and lower airways, respectively. The flow rate through the TSI was set up at $60 \mathrm{~L} / \mathrm{min}$. The cut-off aerodynamic diameter between the two stages at $60 \mathrm{~L} / \mathrm{min}$ is $6.4 \mu \mathrm{m}$, hence particles smaller than this aerodynamic diameter will most likely deposit in the lower impinger and will constitute the 'fine particle fraction' ('FPF') (31). Proliposome powder (25 mg) was filled 


\section{Spray-dried proliposomes for aerosol delivery}

into hydroxypropyl methylcellulose (HPMC; size 3) capsules. Each capsule was loaded into the Miat device which was then connected to the impinger that contained deionized water as collection medium $(7 \mathrm{~mL}$ in the upper stage $(\mathrm{S} 1)$ and $30 \mathrm{~mL}$ in the lower stage (S2). In each experiment, the capsule content was pulled by applying negative pressure $(60 \mathrm{~L} / \mathrm{min})$ through the actuated inhaler device over $5 \mathrm{~s}$. Then, the impinger was dismantled and each stage, the inhaler device and capsule were separately rinsed with deionized water for subsequent drug quantification using HPLC. The total amount of drug in the inhaler device, $\mathrm{S} 1$ and $\mathrm{S} 2$ constitutes the recovered dose (RD) of the drug. The amount of drug deposited in S1 and S2 of the impinger constitutes the emitted dose (ED) calculated as the percentage proportion of the $\mathrm{RD}$ (Eq. 5). The percentage proportion of the drug that is deposited in S2 of the impinger was calculated as the "FPF" (Eq. 6).

$$
\begin{array}{ll}
E D=\frac{S 1+S 2}{R D} \times 100 & E q .5 \\
F P F=\frac{S 2}{R D} \times 100 & E q .6
\end{array}
$$

\subsubsection{Proliposome flowability studies}

Aiming to understand the behaviour of selected formulations, the bulk density of the spray-dried proliposome powder was measured by using the ERWEKA tapped density meter (ERWEKA®p Gmbh, D-63150 Heusenstamm, Germany). A defined mass of powder was poured into a calibrated measuring cylinder and the volume occupied by the powder was recorded. The tapped density of spray dried powder was determined by volume measurement of the tapped mass until no further changes in the powder volume were observed. Hausner ratio and Carr's index, also called Carr's compressibility index, for each spray dried powder were derived according to the following equations:

$$
\begin{array}{cr}
B D=\frac{W}{V} \times 100 & E q .7 \\
T D=\frac{W}{V t} & E q .8
\end{array}
$$


Spray-dried proliposomes for aerosol delivery

$$
\begin{aligned}
& \text { Hausner Ratio }=\frac{V}{V t} \quad \text { Eq. } 9
\end{aligned}
$$

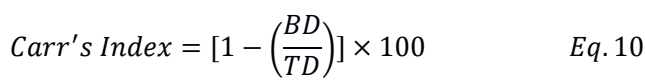

Where $\mathrm{BD}$ and TD are bulk density and tapped density, respectively, and V and Vt are actual volume and tapped volume, respectively.

\subsubsection{Statistical analysis}

All experiments were conducted three times using three different proliposome batches. Statistical significance was studied using one-way analysis of variance (ANOVA) and student's $t$-tests, for comparing more than two sets and two groups of results, respectively. $\mathrm{P}$ values $<0.05$ indicate that difference between compared groups is statistically significant.

\section{Results and discussion}

\subsection{Product yield and drug content uniformity of spray-dried proliposomes}

Table 2 shows the product yield (PY), drug recovery and drug content uniformity of powder formulations. Since spray-drying conditions were the same for all formulations, any difference in PY was attributed to formulation composition, namely, carrier type and lipid to carrier ratio. Spray-drying parameters such as atomizer design, flow rate and temperature of the drying air, solid content of the feed solution can all influence PY of spray-dried powder (32).

For both carriers, a direct relationship was observed between PY and carrier concentration (Table 2). PY of F1 was lower than F2 ( $<<0.05)$, and PY of F2 was lower than F3, F4 and F5 ( $<<0.05)$ (Table 2). However, when PY values of F3, F4 and F5 were compared, the difference was not significant statistically $(\mathrm{P}>0.05)$. Moreover, PY of F6 was significantly $(\mathrm{p}<0.05)$ lower than PY of F7 which, in turn, was significantly $(\mathrm{p}<0.05)$ lower than PY values observed with F8, F9 and F10. Only a trend of higher PY was also found for F9 and F10 when compared to F8 ( $>0.05$ ) (Table 2). The decrease in 


\section{Spray-dried proliposomes for aerosol delivery}

PY of spray-dried formulations is attributed to possible adherence of the sprayed droplets and dry particles to the inner walls of the drying compartment, or because of poor collection of fine powder by the cyclone separator [33]. Thus, the high lipid content of F1, F2, F6 and F7 can be responsible for the low PY of these formulations, causing adherence of lipid to the inner walls of the drying compartment.

The PY of LMH formulations (F6, F7, F8, F9 and F10) was generally higher than PY of proliposomes based on mannitol carrier (F1, F2, F3, F4 and F5), indicating that it is not only lipid content that can affect PY but also carrier type (Table 2). Other reports have demonstrated that glass phase transition $\left(\mathrm{T}_{\mathrm{g}}\right.$ ) of carbohydrates has a prime effect on the behaviour of formulations during spray drying (3437). When the temperature during spray drying is higher than $T_{g}$ of the sugar employed, adherence of formulation components on the walls of the drying chamber may increase, resulting in lower powder yields $(38)$. The $\mathrm{T}_{\mathrm{g}}$ of lactose is $101^{\circ} \mathrm{C}(39,40)$ which is higher than the outlet temperature used in the present study, whilst $\mathrm{T}_{\mathrm{g}}$ of mannitol is lower than the outlet temperature used (41-44), making mannitol-based proliposomes more adhesive with concomitant lower PY than LMH-based formulations (Table 2).

Table 2 also shows the recovery values of salbutamol sulphate (SS). The recovery of drug increased with increasing the carrier ratio in the proliposomes, regardless of carrier type. The enhanced drug recovery is paralleled with the higher PY obtained when higher carrier ratios (i.e. lower lipid concentrations) were used. Thus, low drug recovery for F1, F2, F6 and F7 formulations is attributed to the incorporation of high lipid contents. Table 2 also shows drug content uniformity in the spraydried proliposomes, which was in the range of 90 - 109\%, indicating uniform distribution of SS in the powder. Drug content uniformity using LMH carrier was higher than formulations based on mannitol carrier (Table 2). In an attempt to provide the reasons behind these differences, particle morphology of proliposomes was investigated as illustrated in the subsequent section. 
Spray-dried proliposomes for aerosol delivery

\subsection{Morphology of spray-dried proliposome particles}

Particle morphology of proliposomes presented in Table 1 was studied using SEM (Figure 1). Mannitol-based particles looked spherical regardless of lipid to carrier ratio (Figure 1), coming in agreement with previous investigations employing this carrier (26). Particles of F1 and F2 were spherical and had small sizes, and apparently smooth surfaces, and tended to form large agglomerates (Figure 1a, b). The agglomeration of these two formulations can be attributed to their high lipid content, and may justify their low PY values (Table 2), making their potential for 'deep lung' deposition questionable. By contrast, F3 particles were small, porous and spherical, with less propensity to form agglomerates (Figure 1c). Porosity of particles can enhance their aerosol performance (45). F4 and F5 were small and spherical with apparently smooth surfaces and evidence of particle agglomeration (Figure 1d, e), possibly due to high surface energy of the particles, which commonly increases cohesiveness and compromises flowability (46-48).

By contrast, LMH-based proliposome microparticles were irregular, rough and not similar in size (Figure 2). LMH is practically insoluble in ethanol used as the solvent in the present investigation. Upon atomization during spray drying, it appears that ethanol did not form uniform droplets; hence, the resultant proliposome particles had an irregular shape and wide size distribution. Studies have correlated particle surface morphology with aerosol performance (49). Smooth particles have high flowability and are potentially applicable for aerosolization (50). The irregular shape and rough surface of lactose microparticles can promote the interaction between carrier and drug (49).

Particles that have spherical shape may have high chance for deposition in the peripheral airways, especially when the aerodynamic size is in the range of 1-5 $\mu \mathrm{m}$ (51-54). Thus, LMH-based proliposomes might have lower suitability for delivery from DPI devices than mannitol-based formulations, since LMH-based particles are larger and more irregular in shape (Figure 2). According SEM, the potentially most appropriate proliposome formulation for use as DPIs would be F3 (i.e. using mannitol carrier with 1:6 w/w lipid to carrier ratio) (Figure 1c). 
Spray-dried proliposomes for aerosol delivery

\subsection{Crystallinity of spray-dried formulations}

XR diffraction profiles of SS are shown in Figure 3. The intensity of drug peaks before and after spray drying indicates that the crystalline characteristics of SS were preserved. The intensity peak after spray drying increased slightly, because ethanol can increase powder crystallinity (55-58). Mannitol had high crystallinity before spray drying (Figure 3c); however, the peak intensity decreased by spray drying (Figure 3d), indicating reduced crystallinity of this sugar (59). High amorphous content of solids can facilitate dispersion of powder in aqueous media (60-62), which is advantageous in dry powder formulations.

Spray-dried mannitol is crystalline (Figure 3d). The X-ray diffraction profile of the drug was not detected in the proliposome formulations (Figure 4; Figure 6), because of the low drug concentration when compared to the other formulation components (i.e. mannitol and lipid). Moreover, the drug might have been coated by SPC that is known to be amorphous, resulting in poor detection of crystalline drug traces. Similarly, DSC curve of the formulation F3, for example, did not show a thermogram for the drug. However, the pure drug shows an endothermic melting peak with the onset of about $200^{\circ} \mathrm{C}$

The X-ray diffraction patterns of mannitol proliposomes are presented in Figure 4. The crystalline characteristics of mannitol were dominant in all formulations because of the high content of sugar compared to the other components of the formulations (i.e. drug and lipid). X-ray diffraction profile, as evident from the intensity of the main peak of mannitol-based proliposomes was formulationdependent, when F1-F5 formulations were considered. The intensity of the main peak increased slightly by increasing the ratio of mannitol, owing to the high crystallinity of this type of sugar. The intensity peak of mannitol-based proliposomes (F1-F5) was lower than mannitol alone, indicating other formulations components (mainly the lipid) have decreased powder crystallinity. 


\section{Spray-dried proliposomes for aerosol delivery}

Figure 5 shows the X-ray diffraction profiles of LMH before and after spray-drying in aqueous or alcoholic solutions. As shown in Figure 5a, LMH demonstrated a crystalline profile before spraydrying (Figure 5a), and converted into amorphous because of spray-drying in aqueous solution (Figure 5b), agreeing with previous reports employing this type of sugar (63-67). By contrast, LMH preserved its crystallinity after spray drying from its ethanolic solution, possibly because of the lower solubility of this sugar in ethanol when compared to its aqueous solubility. However, the intensity peak of LMH was diminished by spray drying from ethanol compared to before spray drying (Figure 5c). LMH is crystalline in all formulations due to the high sugar content, regardless of formulation (Figure 6); however, slight differences in the intensity of the main peak was observed when the formulations F6-F10 were compared. Thus, crystallinity increased slightly with increasing LMH ratio in the formulation.

The DSC thermographs for F3 and F8 conformed the preserved crystallinity of both mannitol and $\mathrm{LMH}$, respectively, after spray-drying from ethanolic solution. However, no peaks appeared for the drug in both formulations thermograms (data not shown).

\subsection{Drug entrapment in liposomes generated upon hydration of spray-dried proliposomes}

Drug entrapment efficiency (EE) in liposomes was determined after hydration of the proliposome powder (Table 3). For mannitol-based proliposomes, entrapment differed slightly for different formulations (Table 3). This can be attributed to different proportions of lipid recovered after spray drying, or difference in morphology of proliposome microparticles with accordance to using different formulations. Rough carrier particle surfaces may facilitate carrier-drug interactions due to having high surface area, whilst smooth surfaces may result in loose interactions between the drug and carrier $(49,68,69)$. Thus, the apparently rough surfaces of LMH-based formulations could be responsible for enhanced drug-carrier interactions, facilitating drug encapsulation by liposomes upon hydration. This explains the higher drug entrapment in vesicles generated upon hydration of LMH-based proliposomes compared to mannitol-based formulations (Table 3). Furthermore, F6 and F7 (i.e. lower LMH content; higher lipid proportion) had greater drug entrapment efficiencies than F8-F10 (i.e. 


\section{Spray-dried proliposomes for aerosol delivery}

higher LMH content; lower lipid content) formulations. Thus, the relatively low lipid concentrations in F8, F9 and F10 caused the generation of dilute liposome dispersions; thus, lower drug proportions were encapsulated by the vesicles (Table 3). LMH-based proliposomes with 1:2 lipid to carrier ratio (i.e. F6 formulation) gave the greatest drug entrapment efficiency, because of the high lipid content in this formulation. These findings demonstrated a correlation between PY, particle morphology and drug entrapment efficiency. Other investigators have hypothesized possible hydration of proliposome powders in situ within the lung after inhalation by exploiting the aqueous physiological environment of the lung (24-28). In vivo investigations are merited in the future to explore the validity of this hypothesis. Our ongoing studies involving the use of simulated lung fluids to explore the potential of dehydrated liposome and proliposome formulations when the hydration environment is made from aqueous systems other than simple solutions are supportive to the aforementioned hypothesis (results unpublished).

\subsection{Size analysis of hydrated proliposomes}

The volume median diameter (VMD), also referred to as median size, of liposomes after reconstitution of the powders in deionized water was in the range of $3.38-6.01 \mu \mathrm{m}$ and $3.23-5.96$ $\mu \mathrm{m}$ for mannitol-based vesicles and LMH-based liposomes, respectively (Table 3). Liposome size is an influential factor on drug entrapment, retention time of the vesicle components in the lung, and drug release profile (70). F1 and F6 had the largest VMD measurements and highest drug entrapment efficiencies, whilst F4 and F10 had the smallest VMD values and lowest drug entrapment measurements (Table 3). The high lipid content in F1 and F6 could be responsible for generating the largest vesicles that demonstrated the highest drug entrapment efficiencies. Drug release and absorption of liposome-encapsulated drug are influenced by liposome size and lipid phase composition. For instance, the localized time of terbutaline in the pulmonary system was prolonged by enriching the liposome formulations with $\mathrm{CH}$ or by using phospholipids with saturated alkyl chains (71). Large liposomes and multilamellarity can promote drug entrapment and prolong drug release in 


\section{Spray-dried proliposomes for aerosol delivery}

the lung (72). The Span measurements were approximately 2 or less except for F4, F8 and F9 (Table 3), indicating different polydispersity for different formulations. The high Span values (i.e. polydispersity) could be due to aggregation of liposomes.

\subsection{Zeta potential measurements}

Particles with a net surface charge (negative or positive) may repel each other, causing lower tendency for aggregation during storage, which improves physical stability of formulation stability (73). Furthermore, surface charge on particles, especially negative charge, may influence the interaction of particles with biological membranes (74-76). Liposomes in all formulations had very slightly negative zeta potential values (Table 3), indicating that lipid to carrier ratio, and carrier type did not affect the surface charge of vesicles. These findings support the potential of our liposome formulations, as particles with negative charge may demonstrate enhanced cellular uptake (74-76).

\subsection{Studies of vesicle morphology using transmission electron microscopy (TEM)}

Liposomes generated upon hydration of mannitol-based proliposomes were a mixture of large unilamellar (LUVs) and oligolamellar vesicles (OLVs), while structures generated from LMH-based powders were rich of vesicle clusters and "worm-like" shapes (Figure 7). These findings are in agreement with one of our previous investigations, for liposomes generated from LMH-based proliposomes manufactured using a modified rotary evaporator (77). Based on this TEM study, liposome morphology was unaffected by other formulation factors such as lipid to carrier ratio or lipid composition. The slow dissolution of carrier, may slow the hydration of lipid, resulting in retarded deaggregation of vesicles and formation of elongated bilayer structures (77). By contrast, mannitol-based proliposomes may have better dispersion properties in water, which might be due to the small size, smooth surfaces and spherical shape of mannitol-based particles, as shown earlier by SEM (Figure 1), causing formation of spherical LUVs and OLVs (Figure 7). Thus, the different in 


\section{Spray-dried proliposomes for aerosol delivery}

hydration patterns of phospholipid because of using proliposomes with different morphologies resulted in generation of vesicles with different morphologies (Figure 7). Interestingly, previous studies employing traditional proliposomes manufactured using modified rotary evaporators revealed instant generation of liposomes upon hydration of proliposomes under static conditions (i.e. without shaking) via the 'budding off' mechanism $(22,23,77)$. Further studies should investigate the role of carrier type on the behaviour of liposomes generated from proliposomes.

\subsection{Powder aerosolization performance in vitro}

Proliposome with spherical shapes would be expected to have better flowability, and when combined with having small particle size (i.e. in the 'respirable' range), they become likely to deposit in the lower airways. However, SEM used to evaluate particle morphology does not give information about aerodynamic size. The deposition site of inhaled particle in the pulmonary system is influenced by particle shape and aerodynamic size (78). For this reason, inertial impaction studies using the twostage impinger (TSI) were conducted. Using the MIAT inhaler device, deposition of proliposome particles in the stages of the TSI was studied, in order to determine the recovered dose (RD), emitted dose (ED) and 'FPF' (Figure 8).

Figure 8 shows that the performance of proliposome aerosols was dependent on carrier type and lipid to carrier ratio (Figure 8). The RD for all formulations approached 100\% (95.62-99.79\%), with higher values for LMH-based proliposomes than mannitol-based formulations $(\mathrm{p}<0.05)$ However, the delivery of coarse LMH-based proliposome particles from the capsule was better (i.e. ED was higher) than ED of mannitol-based proliposomes.

The ED was high for all formulations (77.46 - 94.59\%). However, LMH-based proliposomes had higher deposition in the upper stage (S1) of the impinger (i.e. lower 'FPF'). These findings are in agreement with the earlier SEM studies, since all LMH-based proliposome formulations (F6-F10) (shown to have large sizes and irregular shapes; Figure 2 ) had extremely poor 'FPF' (0 - 3.99\%) 


\section{Spray-dried proliposomes for aerosol delivery}

(Figure 8). By contrast, mannitol-based microparticles were smaller and more spherical (Figure 1). Hence, they offered much greater 'FPF' (2.79 - 52.14\%) compared to LMH-based powder. Particles having size of $1-5 \mu \mathrm{m}$ are likely to reach the peripheral airways following inhalation (51). F1 had the lowest FPF amongst mannitol formulations, which can be ascribed to particle agglomeration due to the high lipid content of this formulation. For F2 and F5, the 'FPF' values were 33.57 and $33.63 \%$, respectively. These values were lower than those determined for F3 and F4, which can be attributed to the agglomeration occurring in F2 and F5 formulations because of the presence of small particles.

By contrast, the lower agglomeration tendency of F3 and F4 might be responsible for the enhanced deposition of particles into the lower stage of the TSI (Figure 8). The subsequent section elaborates on studying the characteristics of proliposomes and the generated liposomes, using two distinguished formulations with superior aerosol performance.

\subsection{Additional powder characterization and drug release studies}

Further powder characterization studies and drug release investigations were conducted on best performing proliposome formulations, mainly relaying on the aerosol performance findings of the powders (Figure 8). Proliposome powders exhibited their best performance in terms of 'FPF' when the lipid to carrier ratio was 1:6; thus F3 (mannitol-based proliposomes) and F8 (LMH-based proliposomes) were further investigated in terms of powder flowability and moisture content, and the release profile of SS from the subsequently generated liposomes. Upon reflection on the earlier findings in this study, it was further observed that F3 and F8 formulations exhibited desirable characteristics in terms of drug recovery, PY and drug content uniformity (Table 2). Moreover, as observed earlier with SEM studies, F3 proliposomes were spherical and apparently smooth with low agglomeration propensity (Figure 1c), justifying the superior aerosol performance of this formulation (Figure 8) and supporting the rationale behind conducting flowability and drug release studies on this particular proliposome composition. 
Spray-dried proliposomes for aerosol delivery

Accordingly, flowability studies were conducted on both F3 (as representative for mannitol-based proliposomes) and F8 (as representative for LMH-based formulations). Spray-dried powders of mannitol and LMH were used for comparison with the proliposome formulations to investigate the effect of lipid on powder flowability (Table 4). Flowability was assessed using Carr's compressibility index and Hausner ratio according to the reference published in 1965 (79) and summarized in Table 4. Lipid-free carriers (i.e. spray-dried powders of mannitol or LMH) exhibited 'Fair' flowability according to both Hausner ratio and Carr's index (Table 4; Table 5). When these carriers were used to manufacture spray-dried proliposomes (i.e. F3 as a representative for mannitol-based formulations, and F8 as a representative for LMH-based formulations), the flow characteristics were markedly compromised, so that F3 exhibited 'Poor' flowability, whilst F8 was regarded to have 'Very very poor' flowability according to both Hausner ratio and Carr's index (Table 4; Table 5). Although the flowability findings do not look encouraging for both proliposome formulations (F3 or F8), the emitted dose (ED) of SS from the capsules to the impinger was considerably high, exceeding $80 \%$ (Figure 8), indicating that the 'inspiratory' flow rate through the impinger was sufficiently powerful to pull the proliposome powders from the inhaler device. However, the relatively better flow characteristics of F3 (Table 5) in addition to the spherical morphology, the relatively small physical size, and apparent smooth surfaces of this formulation (Figure 1c) were the prime reasons for the superior 'FPF' value observed for F3 (Figure 8). By contrast, F8 demonstrated very poor 'FPF' (Figure 8), possibly due to the relatively large size, irregular shape and rough surfaces (Figure 2c) and the extremely poor flow properties of the particles (Table 5). The flow rate through the impinger was appropriate to aspirate a large dose of F8 particles, but most of the drug dose was deposited in the upper impinger, resulting in extremely poor 'FPF' values (Figure 8). Particle surface morphology can influence aerosol performance (49) and smooth particles may exhibit better aerosolization characteristics (50). It is worth to mention that the residual moisture contents for both formulations $\mathrm{F} 3$ and $\mathrm{F} 8$ were less than $0.8 \%$ as determined by thermogravimetric analysis $(\mathrm{TGA})$ at $110^{\circ} \mathrm{C}$ (data 
Spray-dried proliposomes for aerosol delivery

\section{not shown). TGA is a well-established analytical tool for the determination of residual moisture}

\section{content in powdered formulations and solid excipients $(80,81)$.}

When the in vitro drug release profiles of F3 and F8 were compared, the difference was insignificant for most intervals studied ( $\mathrm{p}>0.05$ ); however, a trend for faster drug release was observed with the F3 formulation (Figure 9). After $24 \mathrm{~h}$, the cumulative release for SS was 79\% and 72\% for F3 and F8 formulations, respectively, demonstrating advantageous sustained release for both formulations in comparison to the free SS which demonstrated $93 \%$ cumulative release after as short as $8 \mathrm{~h}$ and full release after $24 \mathrm{~h}$ (Figure 9). The drug release findings of F3 and F8 indicate that carrier type (mannitol or LMH) had no significant influence on the drug release profile.

In our opinion, if nebulizable liposome formulations like Arikace ${ }^{\circledR}$ are considered the first generation of inhalable liposome medicines, liposomal and proliposomal DPIs might constitute the secondgeneration formulations. The proliposome formulations introduced in this study offer the rationale of delivering small therapeutic doses of SS with relatively small doses of phospholipid and sugar; this may reduce the risk of 'overwhelming' the lung with large amounts of exogenous lipids. Future investigations should expand to explore the role of materials used to manufacture the capsules that accommodate the powder prior to loading into the inhaler device (2), and the role of inhaler device design $(\underline{83}, \underline{84})$, aiming to maximize formulation output and FPF. Importantly, aerosol flow rate from DPI devices may affect the deposition profile for conventional powders (ㄷ5); thus, studying the role of flow rate through an impinger and its influence on the emitted dose and FPF is part of our ongoing investigations using phospholipid-based powders. Finally yet importantly, in vivo studies using experimental animals are needed in the future to further explore the potential of DPI proliposomes for inhalation to treat pulmonary diseases (e.g. asthma). 
Spray-dried proliposomes for aerosol delivery

\section{Conclusions}

In this study, novel spray-dried proliposome formulations for delivery as dry powders were investigated using LMH or mannitol as carriers and SPC and $\mathrm{CH}$ as lipid composition. The ratio of carrier to lipid has influenced the product yield, particle morphology, and powder crystallinity and deposition pattern in the TSI. The characteristics of proliposome microparticles have accordingly influenced the vesicles generated, in terms of size, surface charge and drug entrapment. The production yield of spray-dried LMH formulations was higher than the yield values shown for mannitol-based proliposomes. X-ray diffraction patterns demonstrated the crystallinity of proliposomes after spray drying from ethanolic suspensions, indicating interaction between the proliposome constituents. SEM, impinger investigations, and powder floewability studies showed mannitol to be a more appropriate carrier for manufacturing DPI proliposome formulations because its particles were spherical, smooth and small after spray drying, and offered higher 'FPF' using the TSI (exceeding 50\%). By contrast, LMH-based proliposomes were irregular in shape, had rough surfaces, larger sizes and poorer flowability, compromising its suitability for as DPI formulations. However, the vesicles generated upon hydration of proliposomes using LMH carrier offered higher drug entrapment efficiencies. The higher drug entrapment in liposomes generated from LMH-based formulations can be ascribed to the larger size of vesicles generated using this carrier. The zeta potential values were slightly negative, regardless of formulation composition. Moreover, TEM showed that mannitol-based proliposomes generated spherical vesicles, while bilayer structures generated upon hydration of LMH-based proliposomes were "worm-like" clusters. Following on the advanced development stages achieved by nebulizable liposome dispersions for inhalation, we expect phospholipid-based dry powders delivered via DPI devices, similar to the formulations developed in this study, to constitute the second generation of inhalable liposomes. 
Spray-dried proliposomes for aerosol delivery

\section{Acknowledgements}

We thank MIAT, Italy for supplying us with the Monodose dry powder inhaler device. We also thank Mr. David McCarthy, Microscopy unit, UCL-School of Pharmacy for the TEM images, and Lipoid, Switzerland for supplying us with SPC (Lipoid S-100).

\section{Conflict of interests}

The authors of this manuscript declare no conflict of interests.

\section{References}

[1] Taylor, K.M., Taylor, G., Kellaway, I.W., Stevens, J., 1989. The influence of liposomal encapsulation on sodium cromoglycate pharmacokinetics in man. Pharm Res, 6:633-636.

[2] Zeng, X.M., Martin, G.P., Marriott, C., 1995. The controlled delivery of drugs to the lung. Int J Pharm, 124:149-164.

[3] Ehsan, Z., Wetzel, J.D., Clancy, J.P., 2014. Nebulized liposomal amikacin for the treatment of Pseudomonas aeruginosa infection in cystic fibrosis patients. Expert Opin Investig Drugs, 23:743749.

[4] Lee, W.-H., Loo, C.-Y., Traini, D., Young, P.M., 2015. Inhalation of nanoparticle-based drug for lung cancer treatment: Advantages and challenges. Asian J Pharm Sci, 10:481-489.

[5] Elhissi, A., 2017. Liposomes for pulmonary drug delivery: The role of formulation and inhalation device design. Curr Pharm Des, 23: 362-372.

[6] Saari, M., Vidgren, M.T., Koskinen, M.O., Turjanmaa, V.M.H., Nieminen, M.M., 1999. Pulmonary distribution and clearance of two beclomethasone formulations in healthy volunteers. Int J Pharm, 181:1-9.

[7] Clancy, J.P., Dupont, L., Konstan, M.W., Billings, J., Fustik, S., Goss, C.H., Lymp, J., Minic, P., Quittner, A.L., Rubenstein, R.C., Young, K.R., Saiman, L., Burns, J.L., Govan, J.R., Ramsey, B., Gupta, R.; Arikace Study Group, 2013. Phase II studies of nebulised Arikace in CF patients with Pseudomonas aeruginosa infection. Thorax, 68:818-825.

[8] Rudokas, M., Najlah, M., Alhnan, M.A., Elhissi, A., 2016. Liposome Delivery Systems for Inhalation: A Critical Review Highlighting Formulation Issues and Anticancer Applications. Med Princ Pract, 25(Suppl 2):60-72. 
[9] Cipolla, D., Blanchard, J., Gonda, I., 2016. Development of Liposomal Ciprofloxacin to Treat

Lung Infections. Pharmaceutics, 8: pii: E6. doi: 10.3390/pharmaceutics8010006.

[10] Elhissi, A.M., Faizi, M., Naji, W.F., Gill, H.S., Taylor, K.M., 2007. Physical stability and aerosol properties of liposomes delivered using an air-jet nebulizer and a novel micropump device with large mesh apertures. Int J Pharm, 2334:62-70.

[11] Ghazanfari, T., Elhissi, A.M., Ding, Z., Taylor, K.M., 2007. The influence of fluid physicochemical properties on vibrating-mesh nebulization. Int J Pharm, 339:103-111.

[12] Najlah, M., Vali, A., Taylor, M., Arafat, B.T., Ahmed, W., Phoenix, D.A., Taylor, K.M., Elhissi, A., 2013. A study of the effects of sodium halides on the performance of air-jet and vibrating-mesh

[13] Elhissi, A.M.A., Karnam, K.K., Danesh-Azari, M.-R., Gill, H.S., Taylor, K.M.G., 2006. Formulations generated from ethanol-based proliposomes for delivery via medical nebulizers. $J$ Pharm Pharmacol. 2006; 58:887-894.

[14] Schreier, H., McNicol, K.J., Ausborn, M., Soucy, D.M., Derendorf, H., Stecenko, A.A., Gonzalez-Rothi, R.J., 1992. Pulmonary delivery of amikacin liposomes and acute liposome toxicity in the sheep. Int J Pharm, 87:183-193.

[15] Mobley, W.C., 1998. The effect of jet-milling on lyophilized liposomes. Pharm Res, 15:149152.

[16] Lu, D., Hickey, A.J., 2005. Liposomal dry powders for pulmonary delivery of proteins. AAPS PharmSciTech, 6:E641-8.

[17] Radhakrishnan, R., Mihalko, P.J., Abra, R.M. Method and apparatus for administering dehydrated liposomes by inhalation. US patent No. 4895719, 1990.

[18] Lo, Y.L., Tsai, J.C., Kuo, J.H., 2004. Liposomes and disaccharides as carriers in spray-dried powder formulations of superoxide dismutase. J Cont Rel, 94:259-272.

[19] Chougule, M.B., Padhi, B.K., Misra, A., 2006. Nano-liposomal dry powder inhaler Amiloride Hydrochloride J Nanosci Nanotechnol, 6:3001-3009.

[20] Chougule, M., Padhi, B., Misra, A., 2008. Development of spray dried liposomal dry powder inhaler of Dapsone. AAPS PharmSciTech, 9:47-53.

[21] Ourique, A.F., Chaves Pdos, S., Souto, G.D., Pohlmann, A.R., Guterres, S.S., Beck, R.C., 2014. Redispersible liposomal-N-acetylcysteine powder for pulmonary administration: development, in vitro characterization and antioxidant activity. Eur J Pharm Sci, 65:174-182.

[22] Payne, N.I., Timmins, P., Ambrose, C.V., Ward, M.D., Ridgway, F., 1986. Proliposomes: A novel solution to an old problem. J Pharm Sci, 75:325-329.

[23] Payne, N.I., Browning, I., Hynes, C.A., 1986. Characterization of proliposomes. J Pharm Sci, 75:330-333. 
[24] Desai, T.R., Wong, J.P., Hancock, R.E., Finlay, W.H., 2002. A novel approach to the pulmonary delivery of liposomes in dry powder form to eliminate the deleterious effects of milling. $J$ Pharm Sci, 91:482-491.

[25] Desai, T.R., Hancock, R.E.W., Finlay, W.H., 2003. Delivery of liposomes in dry powder form: aerodynamic dispersion properties. Eur J Pharm Sci, 20:459-467.

[26] Alves, G.P., Santana, M.H.A., 2004. Phospholipid dry powders produced by spray drying processing: structural, thermodynamic and physical properties. Powder Technol, 145:139-148.

[27] Rojanarat, W., Changsan, N., Tawithong, E., Pinsuwan, S., Chan, H.-K., Srichana, T., 2011. Isoniazid proliposome powders for inhalation - preparation, characterization and cell culture studies. Int J Mol Sci, 12:4414-4434.

[28] Rojanarat, W., Nakpheng, T., Thawithong, E., Yanyium, N., Srichana, T., 2012. Inhaled pyrazinamide proliposome for targeting alveolar macrophages. Drug Delivery, 19:334-345.

[29] Lawaczeck, R., Kainosho, M., Chan, S.I., 1976. The formation and annealing of structural defects in lipid bilayer vesicles. Biochim Biophys Acta, 443:313-330.

[30] Cevher, E., Orhan, Z., Mülazimoğlu, L., Sensoy, D., Alper, M., Yildiz, A., Ozsoy, Y., 2006. Characterization of biodegradable chitosan microspheres containing vancomycin and treatment of experimental osteomyelitis caused by methicillin-resistant Staphylococcus aureus with prepared microspheres. Int J Pharm, 317:127-135.

[31] Hallworth, G.W., Westmoreland, D.G., 1987. The twin impinger: a simple device for assessing the delivery of drugs from metered dose pressurized aerosol inhalers. J Pharm Pharmacol, 39:966972 .

[32] Maury, M., Murphy, K., Kumar, S., Shi, L., Lee, G., 2005. Effects of process variables on the powder yield of spray-dried trehalose on a laboratory spray-dryer. Eur J Pharm Biopharm, 59:565573.

[33] Maa, Y.F., Nguyen, P.A., Sit, K., Hsu, C.C., 1998. Spray-drying performance of a bench-top spray dryer for protein aerosol powder preparation. Biotechnol Bioeng, 60:301-309.

[34] Bhandari, B.R., Datta, N., Howes, T., 1997. Problems associated with spray drying of sugar-rich foods. Dry Technol, 15:671-684.

[35] Bhandari, B.., Howes, T., 1999. Implication of glass transition for the drying and stability of dried foods. J Food Eng, 40:71-79.

[36] Abbas, K.A., Lasekan, O., Khalil, S.K., 2010. The Significance of Glass Transition Temperature in Processing of Selected Fried Food Products: A Review. Modern Appl Sci, 4:3-21.

[37] Truong, V. Glass Transition Temperature and Spray Drying of Sugar-Rich Foods: Modelling and Stickiness. LAP LAMBERT Academic Publishing, Saarbrücken, 2014.

[38] Roos, Y., 1993. Melting and glass transitions of low molecular weight carbohydrates. Carbohydrate Research, 238:39-48. 
Spray-dried proliposomes for aerosol delivery

[39] Roos, Y., Karel, M., 1991. Plasticizing effect of water on thermal behavior and crystallization of amorphous food models. J Food Sci, 56:38-43.

[40] Imtiaz-Ul-Islam, M., Langrish, T.A.G., 2009. Comparing the crystallization of sucrose and lactose in spray dryers. Food Bioprod Process, 87:87-95.

[41] Yu, L., Mishra, D.S., Rigsbee, D.R., 1998. Determination of the glass properties of D-mannitol using sorbitol as an impurity. J Pharm Sci, 87:774-777.

[42] Telang, C., Suryanarayanan, R., Yu, L., 2003. Crystallization of D-mannitol in binary mixtures with $\mathrm{NaCl}$ : phase diagram and polymorphism. Pharm Res, 20:1939-1945.

[43] Yoshinari, T., Forbes, R.T., York, P., Kawashima, Y., 2003. Crystallisation of amorphous mannitol is retarded using boric acid. Int J Pharm, 258:109-120.

[44] Shiga, H., Joreau, H., Neoh, T.L., Furuta, T., Yoshii, H., 2014. Encapsulation of alcohol dehydrogenase in mannitol by spray drying. Pharmaceutics, 6:185-194.

[45] Chan, H.-K., 2006. Dry powder aerosol delivery systems: current and future research directions. J Aerosol Med, 19:21-27.

[46] Byron, P.R., 1986. Prediction of drug residence times in regions of the human respiratory tract following aerosol inhalation. J Pharm Sci, 75:433-438.

[47] Dozan, T., Benkovic', M., Bauman, I., 2014. Sucrose particle size reduction - determination of critical particle diameters causing flowability difficulties. J Hyg Eng Des, 8:3-10.

[48] Wang, J., Shi, Q., Huang, Z., Gu, Y., Musango, L., Yang, Y., 2015. Experimental Investigation of Particle Size Effect on Agglomeration Behaviors in Gas-Solid Fluidized Beds. Ind Eng Chem Res, 54:12177-12186.

[49] Pilcer, G., Wauthoz, N., Amighi, K., 2012. Lactose characteristics and the generation of the aerosol. Adv Drug Del Rev, 64:233-256.

[50] Kou, X., Chan, L.W., Steckel, H., Heng, P.W.S., 2012. Physico-chemical aspects of lactose for inhalation. Adv Drug Del Rev, 64:220-232.

[51] Daniher, D.I., Zhu, J., 2008. Dry powder platform for pulmonary drug delivery. Particuology, 6:225-238.

[52] Scichilone, N., Spatafora, M., Battaglia, S., Arrigo, R., Benfante, A., Bellia, V., 2013. Lung penetration and patient adherence considerations in the management of asthma: role of extra-fine formulations. J Asthma Allergy, 6:11-21.

[53] de Boer, A.H., Gjaltema, D., Hagedoorn, P., Frijlink, H.W., 2015. Can "extrafine" dry powder aerosols improve lung deposition? Eur J Pharm Biopharm, 96:143-151.

[54] Merchant, Z., Buckton, G., Taylor, K.M., Stapleton, P., Saleem, IY, Zariwala, M.G., Somavarapu, S., 2016. Pulmonary delivery of nano-antimicrobial therapeutics to treat chronic pulmonary infections. Curr Pharm Des, 22:2577-2598. 
[55] Harjunen, P., Lehto, V.-P., Martimo, K., Suihko, E., Lankinen, T., Paronen, P., Järvinen, K., 2002. Lactose modifications enhance its drug performance in the novel multiple dose Taifun DPI. Eur J Pharm Sci, 16:313-321.

[56] Larhrib, H., Martin, G.P., Marriott, C., Prime, D., 2003. The influence of carrier and drug morphology on drug delivery from dry powder formulations. Int J Pharm, 257:283-296.

[57] Zhang, Q., Yang, H., Yan, W., 2014. Effect of ethanol on the crystallinity and acid sites of MFI zeolite nanosheets. $R S C A d v, 4: 56938-56944$.

[58] Ebrahimi, A., Saffari, M., Langrish, T., 2015. Developing a new production process for highporosity lactose particles with high degrees of crystallinity. Powder Technol, 272:45-53.

[59] Sebhatu, T., Angberg, M., Ahlneck, C., 1994. Assessment of the degree of disorder in crystalline solids by isothermal microcalorimetry. Int J Pharm, 104:135-144.

[60] Hancock, B.C., Zografi, G., 1997. Characteristics and significance of the amorphous state in pharmaceutical systems. J Pharm Sci, 86:1-12.

[61] Bennett, R.C., Brough, C., Miller, D.A., O’Donnell, K.P., Keen, J.M., Hughey, J.R., Williams, R.O., McGinity, J.W., 2015. Preparation of amorphous solid dispersions by rotary evaporation and KinetiSol Dispersing: approaches to enhance solubility of a poorly water-soluble gum extract. Drug Dev Ind Pharm, 41:382-397.

[62] Shin, G.H., Li, J., Cho, J.H., Kim, J.T., Park, H.J., 2016. Enhancement of Curcumin Solubility by Phase Change from Crystalline to Amorphous in Cur-TPGS Nanosuspension. J Food Sci, 81:N494-501.

[63] White, G.W., Cakebread, S.H., 1966. The glassy state in certain sugar-containing food products. Int J Food Sci Tech Res, 1:73-82.

[64] Pia Fäldt, B.B., 1994. The surface composition of spray-dried protein-lactose powders. Colloids Surf Physicochem Eng Asp, 90:183-190.

[65] Darcy, P., Buckton, G., 1997. The influence of heating/drying on the crystallisation of amorphous lactose after structural collapse. Int J Pharm, 158:157-164.

[66] Wu, L., Miao, X., Shan, Z., Huang, Y., Li, L., Pan, X., Yao, Q., Li, G., Wu, C., 2014. Studies on the spray dried lactose as carrier for dry powder inhalation. Asian J Pharm Sci, 9:336-341.

[67] Amdadul Haque, M., Chen, J., Aldred, P., Adhikari, B., 2015. Denaturation and Physical Characteristics of Spray Dried Whey Protein Isolate Powders Produced in the Presence and Absence of Lactose, Trehalose and Polysorbate-80. Dry Technol, 33:1243-1254.

[68] Kawashima, Y., Serigano, T., Hino, T., Yamamoto, H., Takeuchi, H., 1998. Effect of surface morphology of carrier lactose on dry powder inhalation property of pranlukast hydrate. Int J Pharm, 172:179-188.

[69] Pilcer, G., Amighi, K., 2010. Formulation strategy and use of excipients in pulmonary drug delivery. Int J Pharm, 392:1-19. 
Spray-dried proliposomes for aerosol delivery

[70] Hupfeld, S., Holsaeter, A.M., Skar, M., Frantzen, C.B., Brandl, M., 2006. Liposome size analysis by dynamic/static light scattering upon size exclusion-/field flow-fractionation. $J$ Nanosci Nanotechnol, 6:3025-3031.

[71] Abra, R.M., Mihalko, P.J., Schreier, H., 1990. The effect of lipid composition upon the encapsulation and in vitro leakage of metaproterenol sulfate from $0.2 \mu \mathrm{m}$ diameter, extruded, multilamellar liposomes. J Cont Rel, 14:71-78.

[72] Betageri, G.V., Parsons, D.L., 1992. Drug encapsulation and release from multilamellar and unilamellar liposomes. Int J Pharm, 81:235-241.

[73] Laouini, A., Jaafar-Maalej, C., Limayem-Blouza, I., Sfar, S., Charcosset, C., Fessi, H., 2012. Preparation, characterization and applications of liposomes: state of the art. J Colloid Sci Biotechnol, $1: 147-168$.

[74] Debbage, P., 2009. Targeted drugs and nanomedicine: Present and future. Curr Pharm Des, $15: 153-172$.

[75] Gabizon, A., Price, D.C., Huberty, J., Bresalier, R.S., Papahadjopoulos, D., 1990. Effect of liposome composition and other factors on the targeting of liposomes to experimental tumors: biodistribution and imaging studies. Cancer Res, 50:6371-6378.

[76] Straubinger, R.M., Hong, K., Friend, D.S., Papahadjopoulos, D., 1983. Endocytosis of liposomes and intracellular fate of encapsulated molecules: encounter with a low $\mathrm{pH}$ compartment after internalization in coated vesicles. Cell, 32:1069-1079.

[77] Elhissi, A.M.A., Ahmed, W., McCarthy, D., Taylor, K.M.G., 2012. A study of size, microscopic morphology, and dispersion mechanism of structures generated on hydration of proliposomes. $J$ Disp Sci Tech, 33:1121-1126.

[78] Gupta, P.K., Hickey, A.J., 1991. Contemporary approaches in aerosolized drug delivery to the lung. J Cont Rel, 17:127-147.

[79] Carr, R., 1965. Evaluating flow properties of solids. Chem. Eng. 72:163-168.

[80] Elkordy, A.A., Forbes, R.T., Barry, B.W., 2002. Integrity of crystalline lysozyme exceeds that of a spray-dried form. Int J Pharm, 247: 79-90.

\section{[81] Al-Nimry, S.S., Alkhamis, K.A., 2018. Effect of Moisture Content of Chitin-Calcium Silicate on Rate of Degradation of Cefotaxime Sodium. AAPS PharmSciTech, 19:1337-1343.}

[82] Saleem, I.Y., Diez, F., Jones, B.E., Kayali, N., Polo, L., 2016. Investigation on the aerosol performance of dry powder inhalation hypermellose capsules with different lubricant levels. Int $J$ Pharm, 492:258-263.

[83] de Boer AH, Chan HK, Price R., 2012. A critical view on lactose-based drug formulation and device studies for dry powder inhalation: which are relevant and what interactions to expect? Adv Drug Del Rev, 64:257-274. 
Spray-dried proliposomes for aerosol delivery

789 [84] Yoshida, H., Kuwana, A., Shibata, H., Izutsu, K.I., Goda, Y., 2017. Comparison of 790 Aerodynamic Particle Size Distribution Between a Next Generation Impactor and a Cascade Impactor 791 at a Range of Flow Rates. AAPS PharmSciTech, 18:646-653

792 [85] Abadelah, M., Chrystyn, H., Bagherisadeghi, G., Abdalla, G., Larhrib, H., 2018. Study of the 793 Emitted Dose After Two Separate Inhalations at Different Inhalation Flow Rates and Volumes and 794 an Assessment of Aerodynamic Characteristics of Indacaterol Onbrez Breezhaler ${ }^{\circledR} 150$ and $300 \mu \mathrm{g}$. 795 AAPS PharmSciTech, 19:251-261. 
Spray-dried proliposomes for aerosol delivery

Table 1: Composition of the proliposome formulations manufactured using spray drying

\begin{tabular}{|c|c|c|c|c|c|}
\hline Formulation & $\frac{\text { Lipid : Carrier }}{\underline{(w / w)}}$ & $\frac{\text { Lipids (SPC:CH; 1:1) }}{\underline{(\mathbf{m g})}}$ & $\frac{\text { Mannitol }}{\underline{\text { (mg) })}}$ & $\frac{\underline{\text { LMH }}}{\underline{(\mathrm{mg})}}$ & $\underline{\mathrm{SS}}$ \\
\hline$\underline{F 1}$ & $1: 2$ & $\underline{100}$ & 200 & $=$ & $\underline{10}$ \\
\hline$\underline{\mathrm{F} 2}$ & $\underline{1: 4}$ & $\underline{100}$ & $\underline{400}$ & $=$ & $\underline{10}$ \\
\hline$\overline{\mathrm{F} 3}$ & $\overline{1: 6}$ & $\overline{100}$ & $\overline{600}$ & $\overline{-}$ & $\underline{10}$ \\
\hline$\underline{\mathrm{F} 4}$ & $1: 8$ & $\underline{100}$ & $\underline{800}$ & $=$ & $\underline{10}$ \\
\hline$\underline{\mathrm{F} 5}$ & $1: 10$ & $\underline{100}$ & $\overline{1000}$ & $\bar{z}$ & $\overline{10}$ \\
\hline$\underline{\text { F6 }}$ & $1: 2$ & $\underline{100}$ & $=$ & $\underline{200}$ & $\underline{10}$ \\
\hline$\underline{\mathrm{F} 7}$ & $\underline{1: 4}$ & $\underline{100}$ & $=$ & $\overline{400}$ & $\underline{10}$ \\
\hline$\underline{\mathrm{F} 8}$ & $\underline{1: 6}$ & $\underline{100}$ & $=$ & $\underline{600}$ & $\underline{10}$ \\
\hline$\underline{\mathrm{F} 9}$ & $\underline{1: 8}$ & $\underline{100}$ & = & $\underline{800}$ & $\underline{10}$ \\
\hline$\underline{F 10}$ & $1: 10$ & $\underline{100}$ & $=$ & 1000 & $\underline{10}$ \\
\hline
\end{tabular}



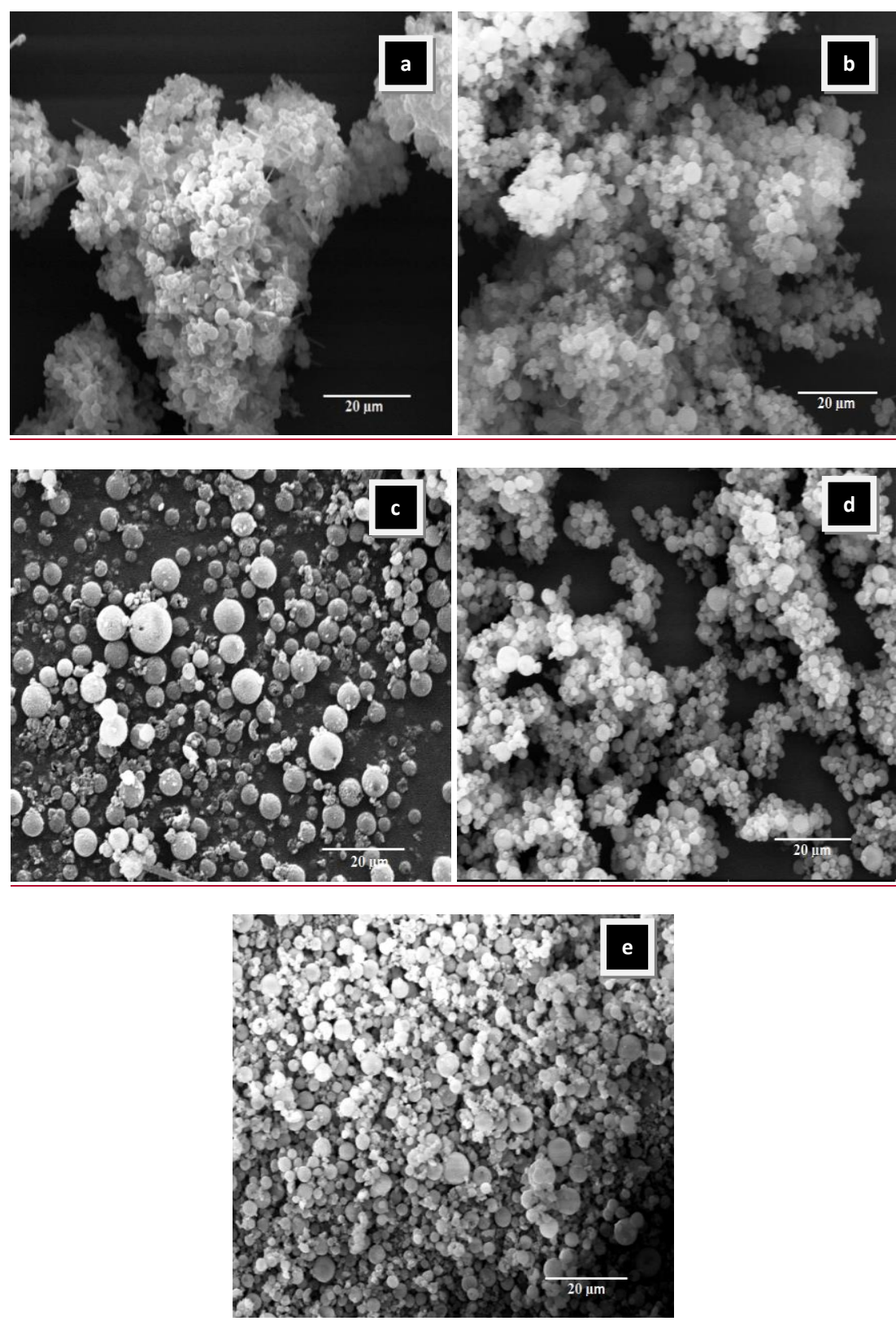

Figure 1: SEM images of mannitol-based proliposomes: (a) F1, (b) F2, (c) F3, (d) F4 and (e) F5 806 
Spray-dried proliposomes for aerosol delivery
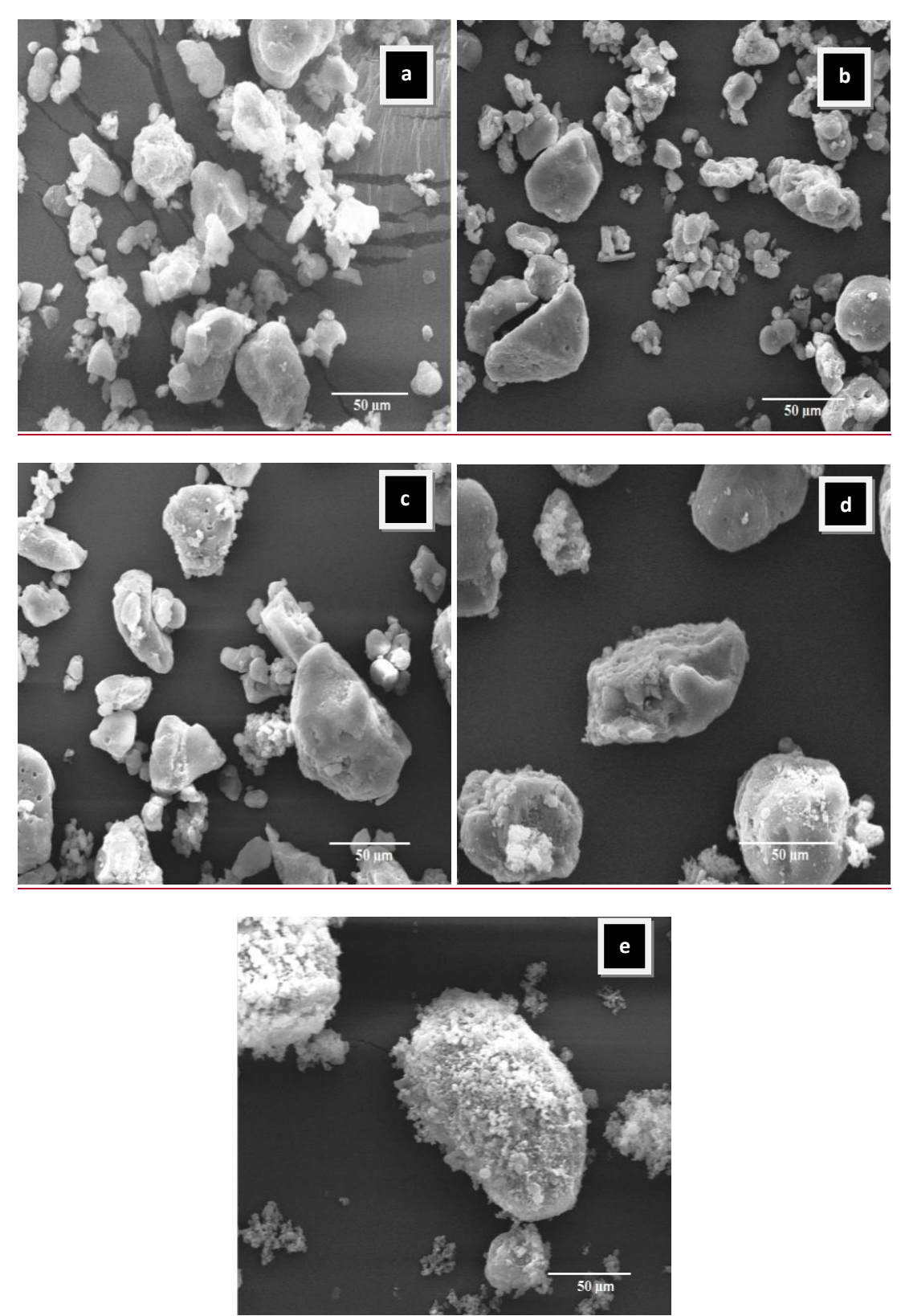

810 Figure 2: SEM images of LMH-based proliposome formulations: (a) F6, (b) F7, (c) F8, (d) F9 and (e) $811 \quad \underline{\mathbf{F 1 0}}$ 
Spray-dried proliposomes for aerosol delivery
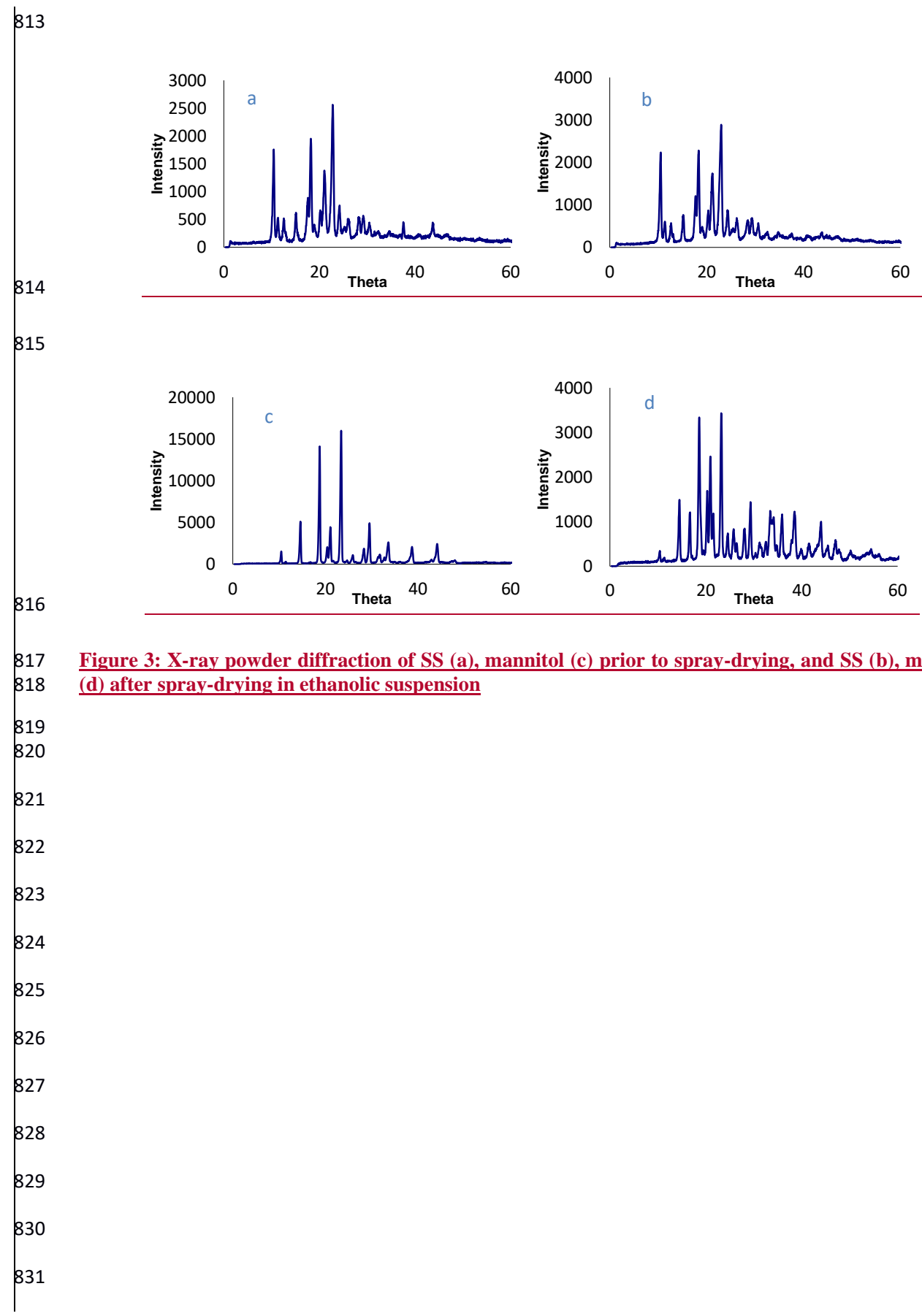

Figure 3: X-ray powder diffraction of SS (a), mannitol (c) prior to spray-drying, and SS (b), mannitol (d) after spray-drying in ethanolic suspension 
Spray-dried proliposomes for aerosol delivery

832

833
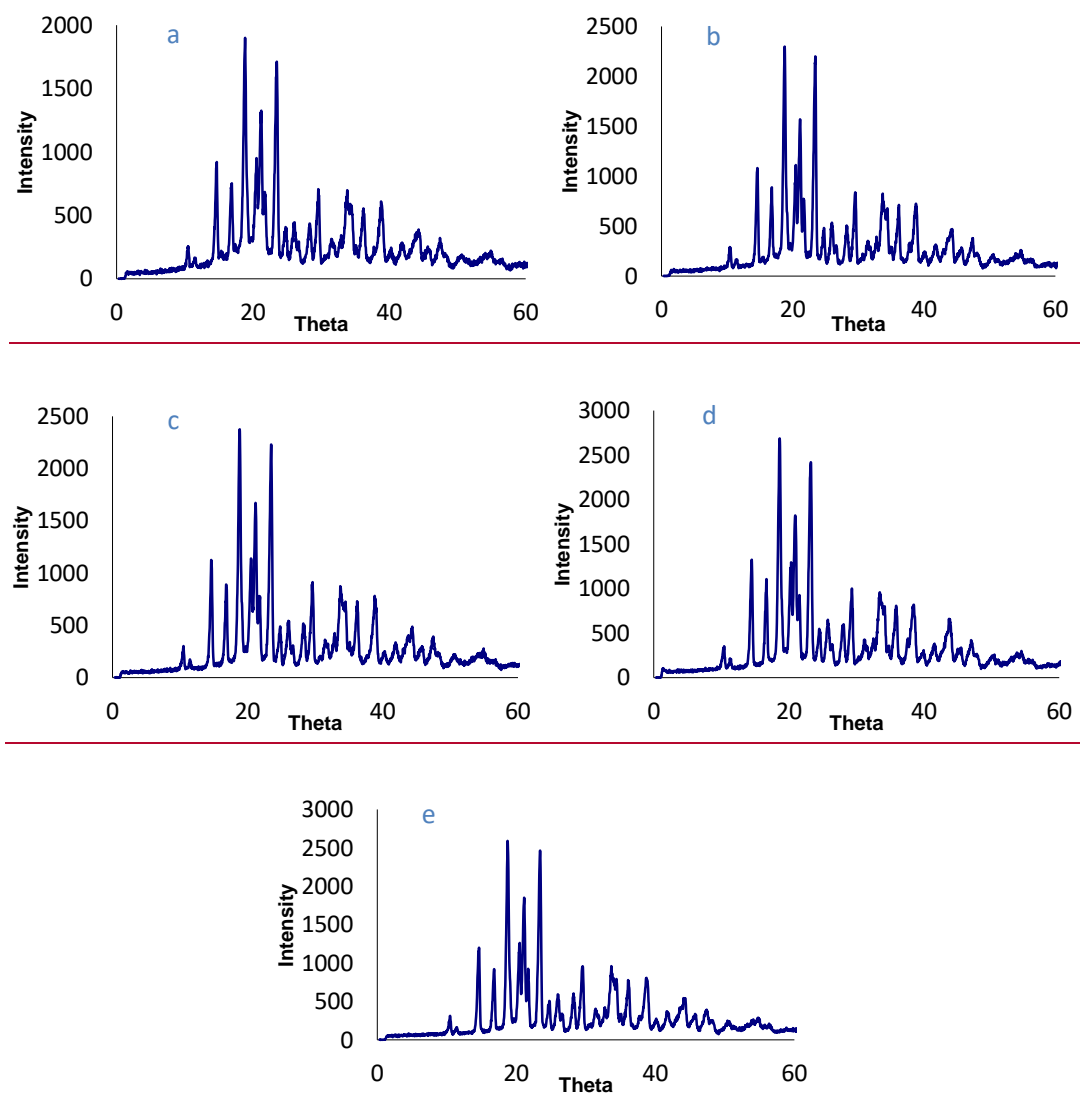

Figure 4: X-ray powder diffraction profiles of mannitol-based proliposomes: (a) F1, (b) F2, (c) F3, (d) F4 and (e) F5 
Spray-dried proliposomes for aerosol delivery
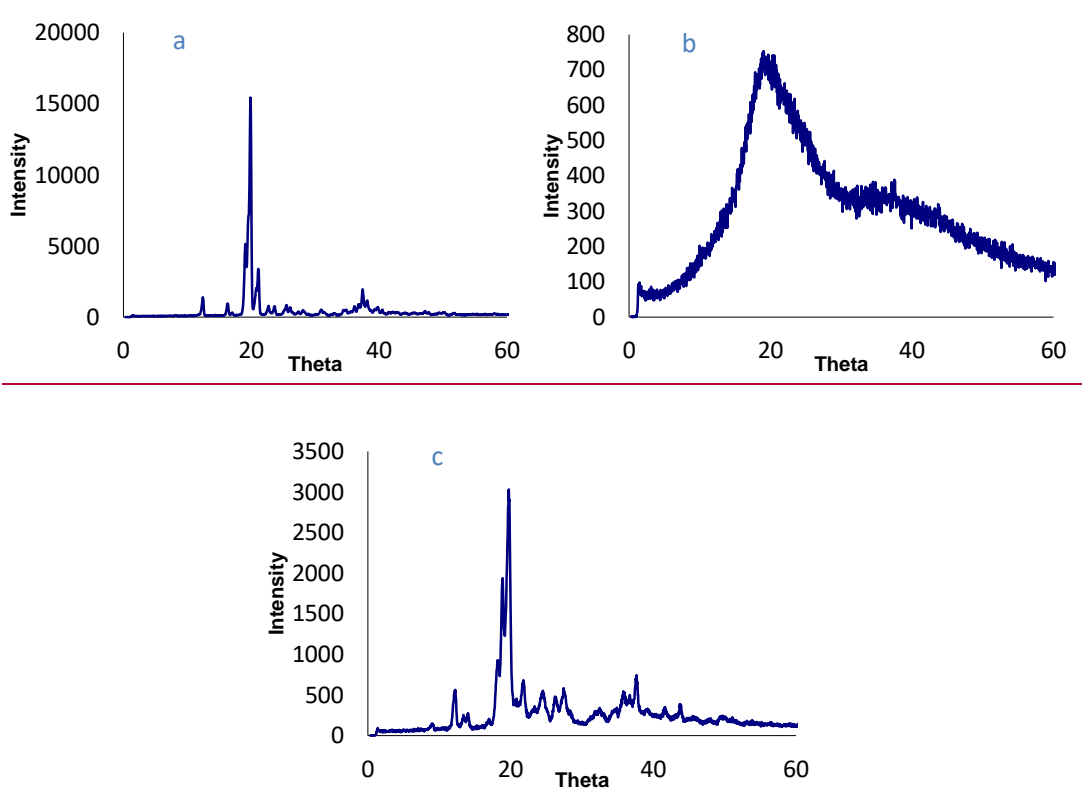

Figure 5: X-ray powder diffraction profiles of LMH: (a) prior to spray-drying, (b) after spray-drying from its aqueous solution and (c) after spray-drying from its ethanolic suspension 
Spray-dried proliposomes for aerosol delivery

858
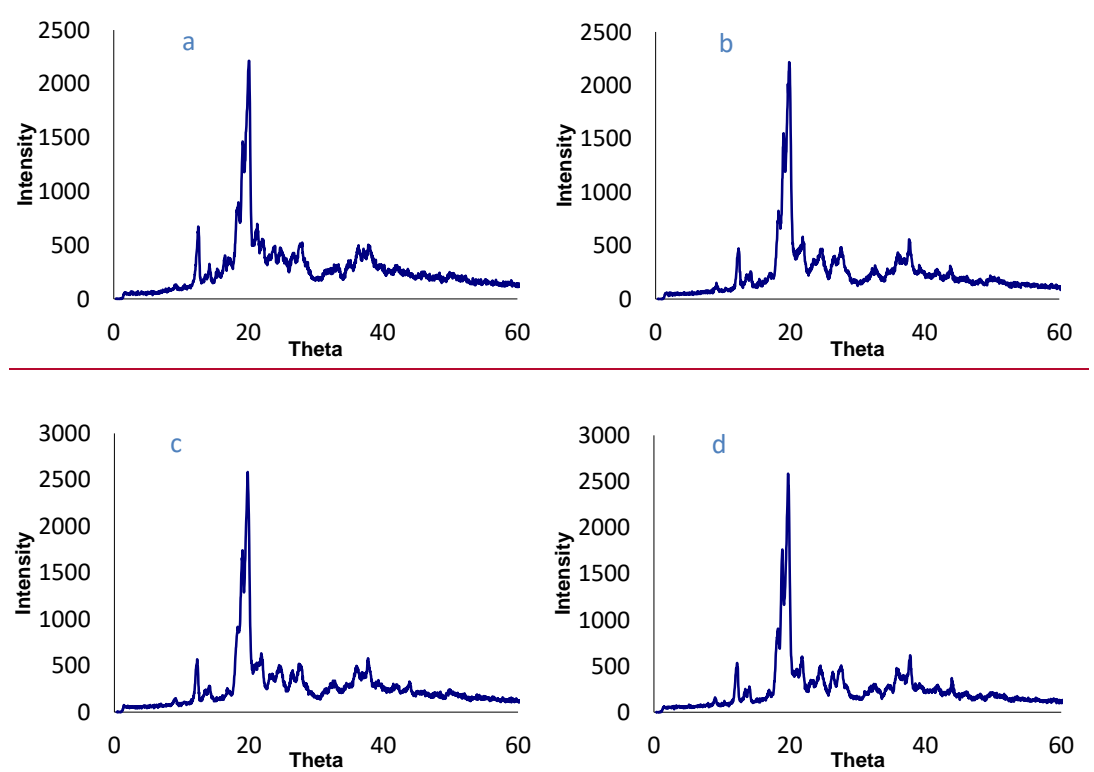

859

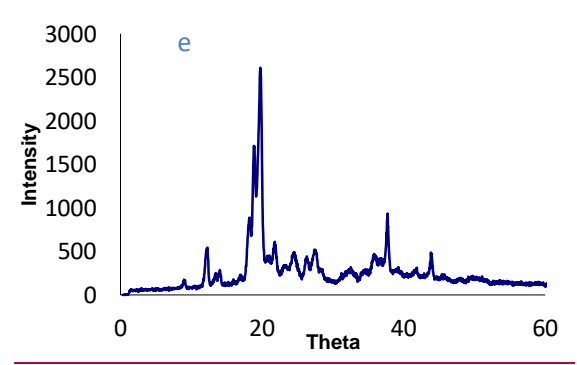

Figure 6: X-ray powder diffraction profiles of LMH-based proliposomes: (a) F6, (b) F7, (c) F8, (d) F9, and (e) F10 
Spray-dried proliposomes for aerosol delivery

865
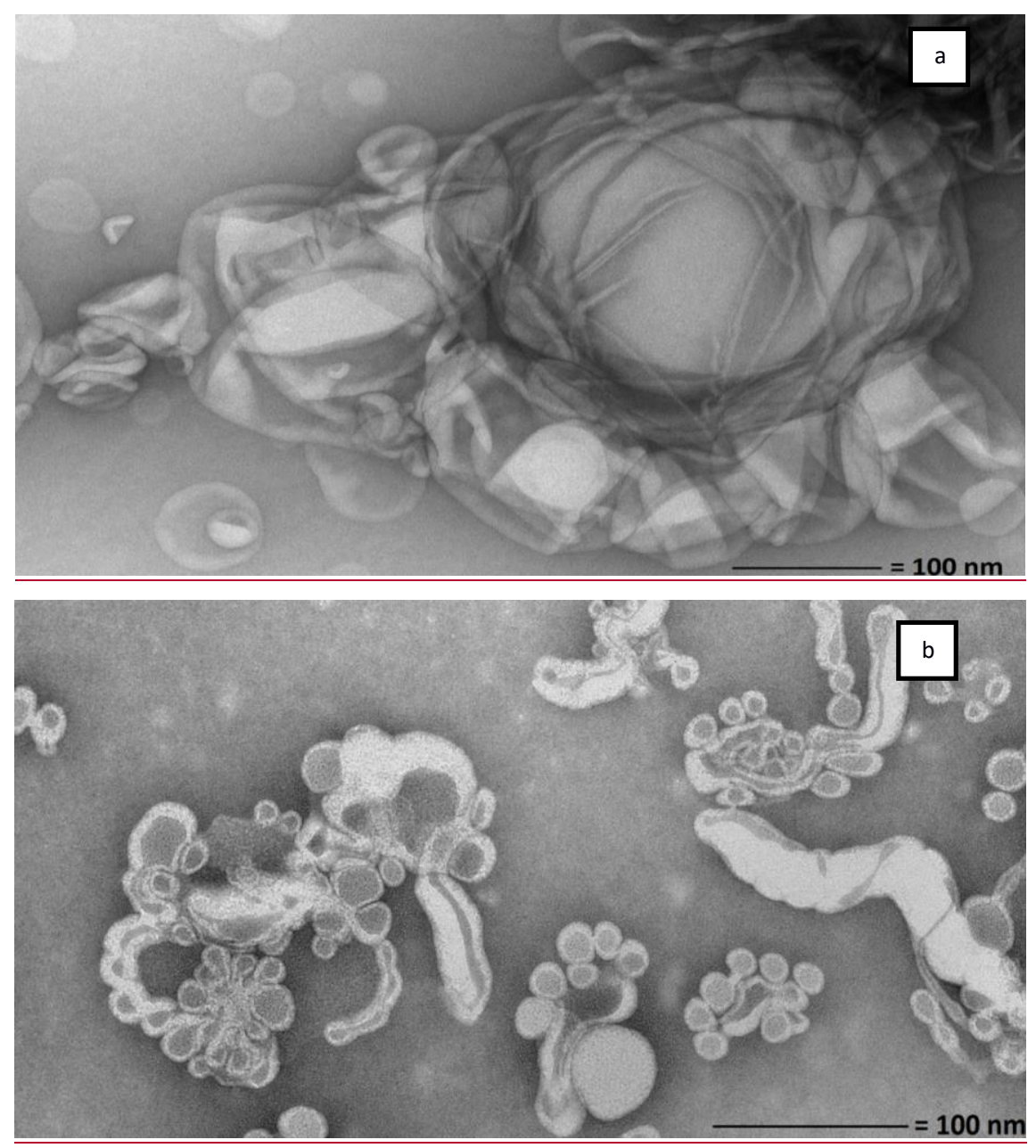

867 Figure 7: TEM of (a) OLV liposomes generated upon manual hydration of mannitol-based proliposomes 868 and (b) elongated worm-like bilaver liposomes and liposome clusters generated from LMH-based 869 proliposomes using 1:6 w/w lipid to carrier

870 
Spray-dried proliposomes for aerosol delivery

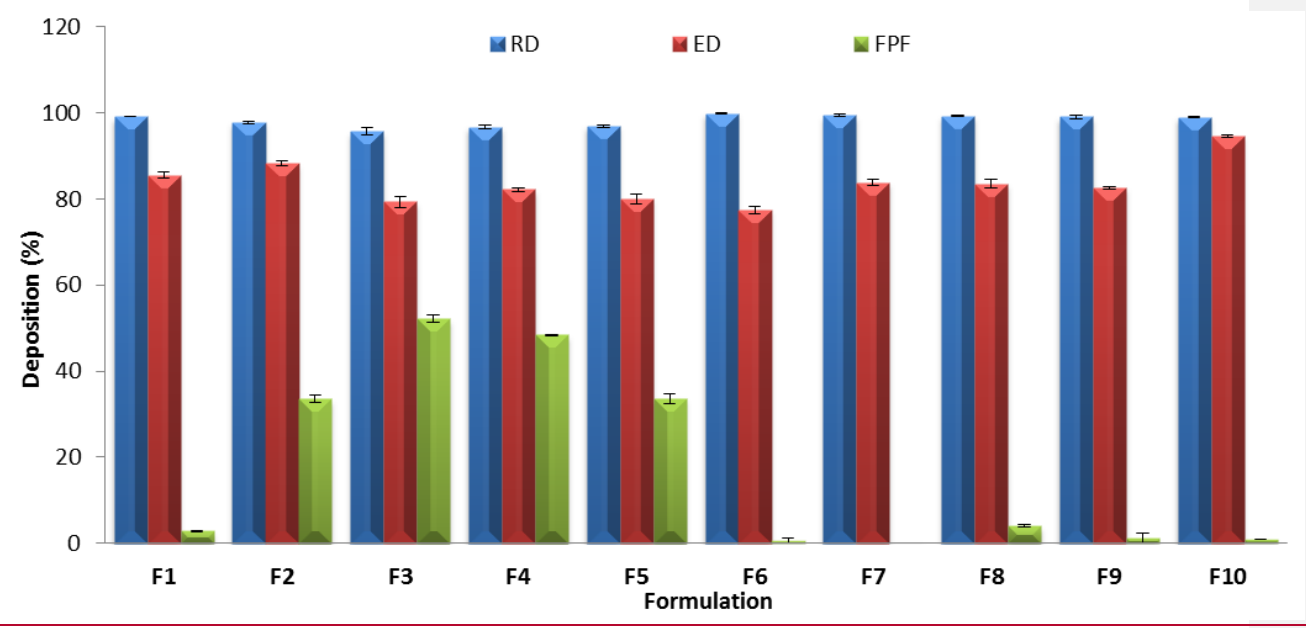

875 Figure 8: Recovered dose (RD; \%), emitted dose (ED; \%) and 'fine particle fraction' ('FPF'; \%) of 876 mannitol-based and LMH-based proliposomes $(\mathbf{n}=3 \pm$ SD)

877

878

879

880

881

882

883

884

885 
Spray-dried proliposomes for aerosol delivery

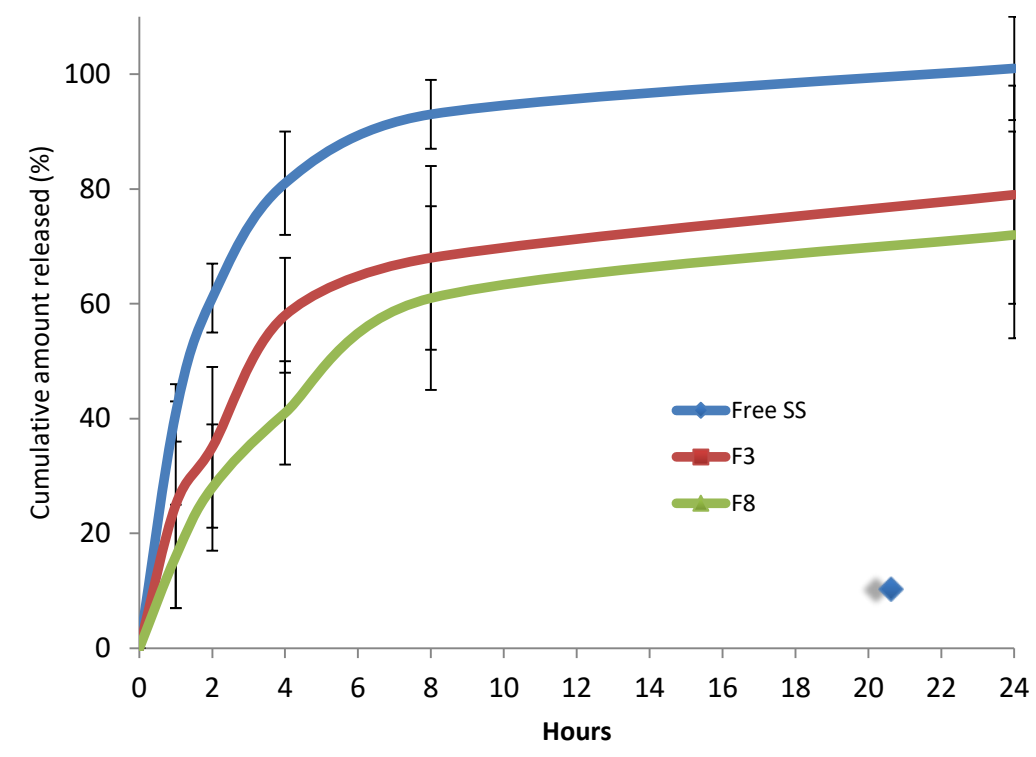

886

887 Figure 9: Drug release profile from liposomes generated from mannitol-based proliposomes 888 (F3) and LMH-proliposomes (F8) in comparison to free SS $(\mathbf{n}=3 \pm \mathrm{SD})$ 